\title{
REGISTROS NOTARIALES DEL ARCHIVO HISTÓRICO MUNICIPAL DE LORCA (MURCIA): APORTACIÓN DOCUMENTAL (SIGLOS XV-XVI)
}

\author{
Diego Antonio Reinaldos Miñarro ${ }^{1}$
}

\section{RESUMEN}

El artículo pretende realizar una aportación documental mediante la selección de tres ejemplos procedentes del rico fondo notarial de que dispone el Archivo Histórico Municipal de Lorca, precedidos de un breve análisis del fondo en cuestión y de las unidades documentales transcritas a nivel histórico y paleográfico.

Palabras clave: Registros notariales, Lorca, época bajomedieval y moderna, documentación, paleografía.

\begin{abstract}
This article attempts to make a contribution document by selecting three examples from the rich collection attorney available to the Municipal Archives of Lorca, preceded by a brief historical and paleographic analysis of this collection and specially of the transcribed documents.
\end{abstract}

Keywords: Notarial records, Lorca, lattle Middle Ages, documentation, paleography.

\section{OBJETIVOS}

El objetivo esencial del presente artículo no es otro que el de dar a conocer tres ejemplos de las diversas unidades documentales conservadas en los ricos registros notariales

Fecha de recepción: 2 de febrero de 2011. Fecha de aceptación: 1 de marzo de 2011

1 Personal Técnico Contratado con cargo al Proyecto de Excelencia financiado por la Junta de Andalucía El Milenio en sus documentos. Corpus Diacrónico del Español del Reino de Granada (1492-1833) CORDEREGRA P09-HUM-4466. Universidad de Granada. Dpto. de Lengua Española. Facultad de Filosofía y Letras. Campus Universitario de Cartuja. E-mail: drm87919@ugr.es 
del Archivo Histórico Municipal de Lorca (Murcia), ${ }^{2}$ precedidos de un breve estudio histórico y paleográfico.

\section{LOS REGISTROS NOTARIALES DEL ARCHIVO HISTÓRICO MUNICIPAL DE LORCA: UN FONDO DE GRAN VALOR PARA LA INVESTIGACIÓN}

Los libros de notas o registros notariales del Archivo Histórico Municipal de Lorca (AHML o AML) constituyen una de las colecciones más valiosas dentro del conjunto documental custodiado en su seno. Así, el archivo, cuyo nacimiento como archivo municipal está vinculado al de la propia institución concejil tras la conquista castellana en 1244, dispone de series documentales municipales que abarcan desde 1257 hasta la actualidad, ${ }^{3}$ sobrepasando hoy día su función primigenia al incorporar entre sus fondos series documentales procedentes de otras instituciones locales e incluso de algunas colecciones particulares, lo que ofrece unas amplias perspectivas de estudio para el investigador. Buen ejemplo de ello es el propio Archivo del Distrito Notarial de Lorca (1492-años 90 del siglo XX), las Actas Capitulares de la Colegiata de San Patricio (1533-1852), el Granero Decimal de Lorca (1568-1836), algunos fondos del antiguo Hospital de San Juan de Dios (Beneficencia) (1547-1978), la Contaduría del Oficio de Hipotecas (1786-1866), Archivo del Sindicato de Riegos de Lorca (1774-1950), Casa de Guevara, Círculo Mercantil, Fondo Alburquerque, Archivo Fotográfico Menchón-Rodrigo, etc.

El Archivo General de Protocolos Notariales del Distrito de Lorca ${ }^{4}$ fue depositado en el año 1979 en las dependencias del Archivo Municipal de la misma ciudad, entonces ubicado en el edificio del Antiguo Pósito, siendo notario archivero don Jesús del Fraile Sarmiento y encargado de dicho archivo don Juan Guirao García. El depósito se efectuó teniendo como base el inventario que entre 1902 y 1905 elaborara el entonces notario archivero don Francisco Escobar Barberán, inventario que sirvió y sirve aún a los notarios como instrumento básico de control de la documentación que de modo ininterrumpido siguen generando las notarías de Lorca y Águilas.

El edificio del Archivo Histórico Municipal se halla desde 2010 en su nueva sede de la calle Selgas, en la conocida como Casa de los Alburquerque, vivienda construida a finales del s. XVI por miembros de esta destacada familia lorquina. El edificio, muy reformado a mediados del siglo XIX para adaptarlo a los gustos de la época y ahora totalmente renovado para cumplir su función como archivo, presenta en su fachada el escudo nobiliario

2 En adelante AHML o AML.

3 Entre ellas podemos destacar los diversos privilegios, mercedes, cartas plomadas, etc. de los diversos monarcas a la ciudad desde el más antiguo de 1257, pasando por los libros de privilegios, Libros de Cuentas y Actas Capitulares del Concejo desde 1474, libros de peticiones o el llamado cartulario de los años 1463-1464. El mejor estudio de la documentación del archivo para la época medieval a día de hoy es el de Isabel GARCÍA DÍAZ, Documentación medieval del Archivo Municipal de Lorca (1257-1504). Estudio y edición, Murcia, Servicio de Publicaciones de la Universidad de Murcia, Ayuntamiento de Lorca, Real Academia Alfonso X el Sabio, 2007.

4 Agradezco profundamente a D. Eduardo Sánchez Abadíe, técnico del Archivo Municipal de Lorca, los datos sobre el origen, evolución y documentación del Archivo de Protocolos Notariales de la ciudad, en los que me baso en las siguientes páginas, además de su predisposición a la hora de facilitarme el acceso a la documentación. 
de este linaje que emparentó en el siglo XIX con los Levasseur y ya en el XX con los Castellar. Consta de tres plantas - baja y dos superiores - , ocupando buena parte de las instalaciones el depósito documental que guarda los ricos y variados fondos a los que hemos aludido anteriormente.

Los registros notariales del distrito de Lorca a los que hacemos referencia en esta contribución comprenden, además de los de esta población, los de Águilas y Puerto Lumbreras, si bien estos últimos sólo incluyen los de los años 1820-1823.

Hasta la fecha de creación del archivo de distrito, los registros notariales debieron conservarse en las propias oficinas de los escribanos, quienes al tomar posesión de la escribanía se hacían cargo de los protocolos de sus antecesores, como venía siendo costumbre en la institución notarial prácticamente desde su creación y más aún desde las diversas disposiciones legales que intentaron regularla, léase fueros, Ordenanzas reguladoras de este oficio en 1503 de Isabel la Católica, ${ }^{5}$ Nueva Recopilación de Felipe II (1566) o Instrucción General de Escribanos de Fernando VI (1750). Es de suponer que conforme fueron amortizándose los 14 oficios con que llegó a contar la ciudad de Lorca (amortización que comenzó a producirse en 1826), los libros de estas escribanías pasarían a engrosar los archivos de otros oficios. Aunque la custodia y traslado de los documentos debía hacerse con todo rigor, la desidia de algunos escribanos con respecto a protocolos antiguos de nulo uso ordinario y algunas causas extraordinarias, determinaron la pérdida irreparable de algunos registros notariales. Aparte de las escrituras que, autorizadas por escribanos antiguos, ya echaba de menos en 1905 el notario archivero Escobar Barberán, la relación más curiosa y paradigmática de pérdida de protocolos, nos la da el escribano José Fernández Briceño quien al tomar posesión de su oficio, como sucesor de su colega Francisco Chico, hace constar en una diligencia lo siguiente:

“El día 30 de Abril de 1802 ocurrió la inundación por el rompimiento del Pantano de Puentes. En la mañana de dicho día falleció D. Francisco Chico, escribano que ejercía esta escribanía, y estando en el féretro en la casa de su morada, que se hallaba en el barrio de San Cristóbal, en el paraje en que totalmente arruinaron las aguas cuantos edificios se encontraron en su corriente, resultó que el cadáver envuelto en la misma corriente lo llevó y dejó en las inmediaciones de la villa de Totana; y este registro (refiriéndose al protocolo que contiene esta diligencia) sufrió la misma suerte porque el referido escribano lo tenía en su casa con otros papeles quizás con el fin de sacar algún testimonio, noticia o apuntación, y esta es la causa de estar deteriorado; advirtiendo que he tenido la paciencia de limpiarlo hoja por hoja del mucho tarquín que lo cubría, encuadernarlo nuevamente y ponerle pergamino también nuevo. Otras escrituras se recogieron sueltas y sumamente destrozadas. Y para que en todo

5 Los especialistas de la ciencia Diplomática no terminan de ponerse de acuerdo en la tipología documental del texto, del que existe una edición facsimilar realizada por Ángel RIESCO TERRERO, "Real Provisión de Ordenanzas de Isabel I de Castilla (Alcalá, 7-VI-1503) con normas precisas para la elaboración del registro público notarial y la expedición de copias autenticadas", Documenta \& Instrumenta, 1 (2004), pp. 47-79. Como puede observarse, el autor habla de una "Real Provisión de Ordenanzas". 
tiempo conste lo acredito por esta nota que firmo en Lorca a 20 de Mayo de 1836. José Fernández Briceño.”

Así pues, no hay constancia escrita de cuándo se creó como tal el Archivo Notarial del Distrito de Lorca. Parece probable que surgiera, como otros muchos, a raíz de la aparición de la Ley Orgánica del Notariado de 21 de febrero de 1862 y la posterior publicación del Decreto-Ley de 8 de Enero de 1869 que ordenaba el establecimiento Archivos Generales de Protocolos de cada distrito notarial, ubicado éste en la cabeza del respectivo Partido Judicial en donde existiera un Juzgado de $1^{\text {a }}$ Instancia. De esta forma, los protocolos de más de 30 años ingresarían en este archivo, que debería estar al cuidado de un notario archivero, nombrado por el Ministerio de Gracia y Justicia, al que el juez de $1^{\text {a }}$ Instancia daría la posesión entregándole el inventario de los documentos y extendiendo un acta original de la que remitiría copia a la Junta del Colegio Notarial. El juez estaba obligado a visitar semestralmente el archivo, y quedaba sujeto en última instancia a la inspección y vigilancia de las Juntas Directivas de los Colegios Notariales y de los regentes de las Audiencias Territoriales. El Reglamento General para la Organización y Régimen del Notariado, de 9 de Noviembre de 1874, desarrollaba más ampliamente todo lo relativo a archivos en el capítulo IX, nombrado "De los Archivos de Protocolos y de las Visitas de Inspección”, que comprende los artículos 93 a 104.

Sin embargo, el cumplimiento tanto del Decreto como del Reglamento debió de ser escaso por la pasividad e indiferencia mostrada por la mayoría de los notarios que, en un primer momento debieron limitarse a conseguir un local donde almacenar la documentación, dejando sin realizar el inventario y sin ingresar periódicamente los protocolos que por ley se estipulaba debían pasar al Archivo General. De hecho, para corregir tal situación fue necesario que se expidiera un Real Decreto, con fecha 14 de Marzo de 1902, que en su exposición de motivos dice así:

“... quiere el Ministro que suscribe evitar dejen de reunirse los documentos públicos para que en todo momento pueda encontrarse cualquiera de ellos, obligando a los notarios a cumplir - manteniendo inalterables los preceptos anteriores - lo que ahora se preceptúa y corrigiendo la apatía e indiferencia que en el cumplimiento de este importante deber se observa en muchos notarios y principalmente en la Juntas Directivas de los Colegios Notariales."

Este Real Decreto, que fijaba la fecha de 31 de Abril como tope para la formación e inventario de los Archivos de Distrito, espoleó definitivamente a los notarios lorquinos con respecto al archivo que tenían a su cargo. A la muerte del anterior notario archivero, Sebastián María de Alberola López, ocurrida en 1899, quedó como archivero interino, por orden de la Junta del Colegio de Albacete, Benedicto Manrique Castrillo quien, con fecha 25 de Abril de 1902 confeccionaba el primer inventario del archivo, no exento de una introducción exculpatoria que literalmente dice así:

"Que a la muerte del notario D. Sebastián María de Alberola y López, que desempeñaba el cargo de archivero de protocolos de este distrito, por orden de 
la Junta del Colegio de Albacete, se me ordenó que interinamente se me hiciera entrega del archivo. Estaba situado en varios huecos reducidos, ruinosos e inmundos inmediatos al tejado del edificio que fue Audiencia de lo criminal; protocolos y papeles formaban montones sin orden ni concierto alguno, e imposible era en tales lugares hacerse cargo de los que allí había ni ordenar nada. Añádase a ésto que el archivero señor Alberola no tenía inventario ni nota alguna de los documentos que estaban bajo su custodia ... Una vez tomada posesión, más bien simbólica que real, por el que suscribe de lo impropiamente llamado archivo se gestionó por el mismo, con la ayuda eficaz de sus compañeros, para que el Ayuntamiento cediera un lugar adecuado al objeto señalando, provisionalmente, lo que fue sala de sesiones públicas de la suprimida Audiencia ..."

Al finalizar la primera adición que hizo al inventario, puntualizaba:

“... Por último hago constar que debido sin duda al estado de completo abandono que durante muchos años se ha encontrado el archivo, diseminados los volúmenes en diferentes lugares, existen hojas sueltas de escrituras públicas, tomos incompletos y muy mal conservados, notándose a la vez la falta de volúmenes en algunos años. Lorca 31 de Enero de 1903."

Este inventario, muy sucinto, recogiendo solamente el número total de tomos históricos agrupados por siglos hasta la primera mitad del siglo XIX y relacionando por notarías y años a partir de 1851, cuenta con varias adiciones de las cuales la primera está hecha por el propio Manrique y las demás por el varias veces mencionado Francisco Escobar Barberán, nombrado notario archivero por Real Orden de 13 de Noviembre de 1903. Escobar fue el verdadero artífice de la organización del Archivo General del Distrito. Dos largos años le costó remontar la situación de abandono en que se encontraba, mejorando notablemente sus condiciones de instalación y redactando un nuevo y más pormenorizado inventario que se ajustaba estrechamente a lo que disponía el artículo 96 del Reglamento de 1874: número de protocolos, número de folios de cada volumen, notarios autorizantes y años que comprenden. El inventario partía de una previa clasificación por siglos separando los protocolos por años y dentro de cada año por notarios. La segunda mitad del siglo XIX estaba organizada por notarios, figurando aparte reseñados los protocolos de particiones notariales y las judiciales, así como los libros indicadores y otros legajos de documentos sueltos. Al comienzo de este nuevo inventario colocó Escobar un acta impresa, firmada en Lorca a 31 de Diciembre de 1905, con la que afortunadamente contamos y que en su totalidad es como sigue:

"La importancia de los trabajos que supone la formación del presente inventario, labor realizada en el transcurso de tres años consecutivos, puede apreciarse con todo exactitud, recordando el estado lamentable en que se encontraban los libros, protocolos y legajos del Archivo al ocurrir el fallecimiento del Notario Archivero D. Sebastián María de Alberola López. El acta extendida a la sazón por el Delegado del Distrito, D. Benedicto Manrique y Castrillo, 
prueba elocuentemente el completo abandono en que se les tenía. Gran número de protocolos estaban hacinados en montón informe y en oscuros y ruinosos desvanes de la antigua Casa del Corregidor; otros se hallaban ignorados en los Archivos de diversas oficinas públicas y algunos en poder de particulares, sucesores y parientes de antiguos escribanos de este número.

Era urgente el arreglo de esta importantísima Oficina y las últimas disposiciones publicadas sobre reorganización de archivos de protocolos, nos decidieron a acometer tan difícil empresa que por otra parte nuestro patriotismo no podía dejar abandonada. Este propósito fue acogido con entusiasmo por mis dignos compañeros de residencia Señores Manrique y D. Fernando Giménez Díaz, quienes ni por un momento le han regateado su eficaz y valiosísima cooperación.

Las primeras gestiones se encaminaron a conseguir un local apropiado para la decorosa instalación del Archivo y después de vencer no pocas dificultades, se nos concedió por este Excmo. Ayuntamiento, la que fue Sala de sesiones públicas en la suprimida audiencia de lo Criminal de esta ciudad que por su amplitud y buen estado de conservación, reúne condiciones inmejorables para el caso.

Se han hecho que ingresen en el Archivo los libros y protocolos que obraban esparcidos en distintos lugares, habiéndose tenido que sustanciar un laborioso expediente ante el Ministerio de Obras Públicas para la incautación de los que aparecían en el Sindicato de Riegos; se ha colocado una estantería completa para la mejor conservación de los volúmenes, encuadernándose muchos de éstos; se ha puesto luz eléctrica en el local del Archivo, reforzándose sus condiciones de seguridad y se han introducido otras reformas no menos útiles en su decorado y ornamentación. Por último complemento y remate de estos trabajos es el inventario que subsigue, en el que con toda la precisión posible se anotan los años, nombres de los notarios, número de folios de cada tomo y observaciones que merecen.

En la relación de los volúmenes se sigue un orden rigurosamente cronológico, excepto en la segunda mitad del siglo XIX que figuran clasificados por Notarías y dentro de éstas por años. Además los tomos llevan su número general de orden y en la estantería se han colocado tablillas donde se consignan los años que cada leja comprende, para hacer más prontas y fáciles las búsquedas.

Lorca treinta y uno de Diciembre de 1905

El Notario Archivero Francisco Escobar."

El trabajo desarrollado por Escobar obtuvo rápidamente una respuesta oficial de felicitación. En 1908 recibía los elogios del señor Cobián, magistrado del Supremo e inspector general de tribunales, que giraba una visita de inspección al archivo. De igual modo se manifestó la Junta Directiva del Ilustre Colegio Notarial de Albacete y la Dirección General de los Registros y del Notariado, quedando todo ello incluido en su expediente personal. En 1914 el Colegio de Abogados de Lorca, por escrito de su decano el señor 
Mellado Benítez, reconocía también la meritoria labor de Escobar haciendo constar "los singulares méritos adquiridos ... en aras del interés público". Escobar Barberán ejerció el cargo de archivero de modo vitalicio. A su muerte, en 1934, el archivo contaba con un inventario actualizado y en condiciones de ser continuado con poco esfuerzo, alcanzando un número total de 2741 volúmenes.

Desde el año 1932 el local del Archivo Notarial del Distrito de Lorca deja de ser la antigua sala de la Audiencia. Esta fue ocupada por el Instituto Provincial de Higiene concedido a Lorca, por lo que el Ayuntamiento ofreció a los notarios tres habitaciones y un pasillo contiguo al mencionado salón destinado entonces a secretaría judicial del Juzgado de $1^{\text {a }}$ Instancia e Instrucción y Colegio de Abogados, aceptando esta cesión el Colegio Notarial. Luego, como hemos señalado, el Archivo volvió a su emplazamiento originario en el Antiguo Pósito, en la plaza del Caño, lugar donde ha estado ubicado hasta mayo de 2010 el Archivo Histórico Municipal de Lorca que lo custodia.

El último trabajo de descripción de fondos del Archivo Notarial del Distrito de Lorca, realizado sobre la base del antiguo inventario y la revisión sistemática de los protocolos, afectó a la documentación comprendida entre 1492 y 1893. En total eran 2583 unidades archivísticas de las que 2544 corresponden a protocolos notariales, 5 son legajos con documentación de diversa procedencia y 34 legajos de particiones judiciales.

Los protocolos notariales cuentan en la actualidad para su manejo con un índice topográfico, un índice onomástico por localidades, un inventario alfabético por localidades y un índice cronológico también por localidades. Para la elaboración del inventario se tomó como modelo el hecho por Matilla Tascón para el Archivo Histórico Provincial de Madrid.

A día de hoy el número de protocolos notariales depositados en el Archivo Histórico Municipal de Lorca es de más de 4.426 tomos, abarcando cronológicamente desde 1492 hasta los años 90 del siglo XX, fecha esta última de los últimos ejemplares ingresados, que en su mayor parte corresponden a escrituras de protestos que desde los años 60 se agrupan en tomos independientes.

La importancia de la documentación notarial a la que venimos aludiendo desde el principio se debe por un lado a su excepcionalidad para el conjunto del antiguo reino de Murcia, ya que, además de los de Lorca, prácticamente sólo contamos con los fondos del Archivo Histórico Provincial de Murcia o Archivo General de la Región de Murcia ${ }^{6}$ y de algunos archivos municipales (Calasparra, Totana y Yecla), ${ }^{7}$ además de los fondos del

6 Para más detalle véase: HERRERO PASCUAL, A. Ma y MONTOJO MONTOJO, V.: "Fondos documentales de instituciones judiciales en el Archivo Histórico Provincial de Murcia”, en III Jornadas de Castilla La Mancha sobre Investigación en Archivos "La Administración de Justicia en la Historia de España” (Guadalajara, 11/14-11-1997), Archivo Histórico Provincial de Guadalajara, ANABAD Castilla La Mancha y Asociación de Amigos del Archivo Histórico Provincial de Guadalajara, Guadalajara, 1999, tomo 2, pp. 867-888. Disponible en red: http://www.archivistica.net/Textos/FONDOJUD.pdf (Fecha de consulta: 07/05/2011). Un estado de la cuestión del notariado en el antiguo reino de Murcia puede encontrarse en un reciente artículo mío al respecto: REINALDOS MIÑARRO, D. A., "Los escribanos de cámara y del número de Lorca (Murcia) a finales de la Edad Media a través de los protocolos notariales (1466-1521)", Miscelánea Medieval Murciana, XXXIV, 2010, pp. 103-118, en especial 103-106.

7 En el caso de Yecla contamos con la aportación de PUCHE LORENZO, M. A. (Ed.): Documentos jurídico-notariales del siglo XVI (1534-1590) del Archivo de Protocolos Notariales de Yecla, CODOM 22, Murcia, Real Academia Alfonso X el Sabio, 2002. 
Archivo de la Catedral de Murcia. ${ }^{8}$ Por otro lado, el interés de esta documentación radica en su riqueza y variedad temática, lo que le otorga un gran valor para la investigación en lo que concierne al estudio de la propiedad de la tierra y su transmisión, del regadío y las infraestructuras hidráulicas, de las formas de explotación económica, de la composición de los cultivos, las relaciones sociales y la conformación de las oligarquías, el mundo de la frontera, la vida cotidiana, la vestimenta, el mobiliario doméstico, la Historia del Derecho, la Historia de la Lengua, la toponimia, los modos de vida... Todo ello teniendo en cuenta la necesidad de su cotejo con otras fuentes documentales del periodo que se estudie, caso de las Actas Capitulares, Libros de Peticiones, los llamados Libros del Agua... además de con otras fuentes de diversa índole (arqueológicas, artísticas e iconográficas, orales, etnográficas, etc.), siendo todas ellas sometidas a su correspondiente crítica.

Y es que hay que tener en cuenta que las fuentes notariales, pese a que tradicionalmente han sido consideradas más objetivas que otras fuentes documentales, tienen también muchas limitaciones, ya que, gracias a los avances producidos en la crítica histórica en los últimos años, se ha visto que ninguna fuente es objetiva y que los datos contenidos en ellas dependen de la voluntad de las personas o instituciones que las producen, así como de la interpretación que el investigador les da en función de los presupuestos con los que a ellas se acerca, de los que debe liberarse en la medida de lo posible.

De esta forma, podríamos resumir las limitaciones o peligros de estas fuentes en los siguientes puntos:

- Grado de representatividad discutible, en tanto en cuanto sólo son capaces de acudir a un notario a inventariar sus bienes los miembros de un grupo social concreto, generalmente perteneciente a las esferas más elevadas de la sociedad, que, en ningún modo, representa al común de la misma.

- Baja fiabilidad, por posibles omisiones, exageraciones e interpolaciones, lo que es lógico en este tipo de fuentes, que muchas veces se hacían sin la presencia directa del notario. Además, éste da fe única y exclusivamente de lo que el cliente pide, tendiéndose a resaltar $\mathrm{u}$ omitir muchas veces los aspectos que coinciden con los intereses del mismo.

- Problemas en el uso del lenguaje que dificultan la labor del investigador, debido a la polisemia, vaguedad o ambigüedad de los términos empleados en las descripciones de objetos o en la situación de lugares, lo que hace necesario un estudio lingüístico a fondo y una colaboración con la Filología para salvar posibles dificultades o errores interpretativos, además de para observar la procedencia y etimología de las palabras con las que los documentos se refieren a cada objeto o

8 Si bien nos estamos remitiendo única y exclusivamente a la institución civil del notariado, merecen la pena destacarse los fondos depositados en el Archivo de la Catedral de Murcia. Vid. MARSILLA DE PASCUAL, F. R.: El Cabildo de la Catedral de Murcia en el siglo XV: el escritorio capitular, la Chancillería episcopal, Tesis Doctoral, Universidad de Murcia, 1990, 3 vols., inédita; "Notariado eclesiástico de la Iglesia de Cartagena (s. XV): I. Los signos notariales", Anales de la Universidad de Alicante. Historia medieval, $\mathrm{n}^{\circ}$ 10, 1994-1995, pp. 233-260 e "Introducción al protocolo eclesiástico de Juan Sánchez, notario apostólico de Murcia (siglo XV)", Estudis castellonencs, nº 6, 1994-1995, pp. 815-828. OLIVARES TEROL, M ${ }^{\mathrm{a}}$ J.: El Cabildo de la Catedral de Murcia en el siglo XVI: escribanía y audiencia episcopales, Tesis Doctoral, Universidad de Murcia, 1994, inédita. 
lugar. También se hace necesaria la colaboración con la Historia del Derecho, dada la enorme cantidad de formulismos jurídicos y notariales presentes.

- Las categorías mentales y culturales que se pueden inferir en este tipo de documentos no se corresponden con las nuestras. Es un mundo distinto, de manera que un acercamiento a la época tendrá que hacerse teniendo en cuenta esta problemática e intentando salvar distancias con el pasado, superar clichés y ser conscientes de esta situación.

- Y relacionado con lo anterior, las categorías descriptivas tampoco van a corresponderse en ninguna medida con los intereses del investigador, ya que responden a otros objetivos distintos.

No obstante, las fuentes que a continuación se presentan, considerando los aspectos señalados anteriormente a la hora de proceder a su estudio, y mediante una colación con el resto de fuentes disponibles, se nos antojan como de capital importancia para el conocimiento del periodo bajomedieval y moderno en Lorca y el ámbito del Sureste peninsular e incluso la Historia de España en general, dada su riqueza y variedad de componentes de análisis temático.

\section{BREVE ESTUDIO PALEOGRÁFICO Y DIPLOMÁTICO DE LOS DOCUMEN- TOS PRESENTADOS}

A pesar de que las tres unidades documentales presentadas se acompañan de una regesta diplomática en la que se consignan los datos esenciales del documento (data crónica y tópica, resumen del contenido, tradición documental, siglas del fondo o archivo que los custodia, signatura archivística, tipología diplomática, materia escriptoria, estado de conservación, tintas, tipo de letra, lengua y elementos externos como signos notariales o rúbricas), se hace necesario hacer referencia en estas líneas a las características que se observan a nivel paleográfico-diplomático de los documentos presentados.

Así, a nivel paleográfico, hemos de señalar que las dos primeras unidades documentales se encuentran escritas en el tipo de letra más común en la documentación del momento: la denominada escritura "cortesana". 9 Se trata de un tipo gráfico que aparece hacia 1425 y que hasta mediados del siglo XVI será de uso muy frecuente en la documentación emanada de la cancillería regia y de las escribanías públicas. Su época de mayor esplendor

9 Para un conocimiento más profundo y detallado de este tipo gráfico y del siguiente (cortesana y procesal), ambos pertenecientes para la mayoría de los investigadores al sistema de escritura de las letras góticas, véase ROMERO TALLAFIGO, M., RODRÍGUEZ LIÁÑEZ, L., SÁNCHEZ GONZÁLEZ, A.: Arte de leer escrituras antiguas: paleografía de lectura, Universidad de Huelva, 1995; RIESCO TERRERO, A., RUIZ GARCÍA, E., DOMÍNGUEZ APARICIO, J. y SÁNCHEZ PRIETO, A.B.: Aproximación a la cultura escrita, Madrid, 1995; RIESCO TERRERO, A. (ed.): Introducción a la Paleografía y la Diplomática General, Madrid, Síntesis, 1999, y del mismo autor "La típica "letra cortesana" de los reinos de la Corona de Castilla en los tiempos de los Reyes Católicos, Hidalguía: la revista de genealogía, nobleza y armas, no 304-305, 2004, pp. 475-496; MARÍN MARTÍNEZ, T. y RUIZ ASENCIO, J. M.: Paleografía y Diplomática, Madrid, UNED, 1998, 2 vols., vol. 2; CASADO QUINTANILLA, B., Láminas de la cátedra de Paleografía y Diplomática, Madrid, UNED; y del mismo autor, "De la escritura de albalaes a la humanística: un paréntesis en la historia de la escritura", II Jornadas Científicas sobre Documentación de la Corona de Castilla (siglos XIII-XV), Madrid, Universidad Complutense de Madrid, 2003, pp. 11-40, pp. 31-36 especialmente. Este artículo es de especial interés sobre todo en lo que se refiere al análisis de las peculiaridades gráficas de la letra cortesana. 
coincidió precisamente con el reinado de los Reyes Católicos, el de Felipe I y doña Juana y las regencias de Cisneros y don Fernando.

En cuanto a los rasgos que mejor describen este tipo gráfico destaca la tendencia al envolvimiento de letras y palabras mediante espirales que resultan como consecuencia del alargamiento de los astiles y fugas de las mismas. Este ductus en espiral tenía como objetivo escribir sin levantar el útil escriptorio del papel, con lo cual se terminaban uniendo dichos astiles y fugas con los signos generales de abreviación.

Entre las grafías más llamativas podemos destacar la "a" en forma de fantasma y la llamada "a" de lineta, una especie de "u" cerrada en su parte superior con un trazo recto mediante el cual se une con la letra siguiente. Otras grafías representativas son los diferentes tipos de "s" ("s" alta, "s" sigmática, "s" de doble curva...), la "g" y la "q", muy similares o los diferentes tipos de "r" (con caído descendente, parecida a la tipográfica actual...). También existe una continuidad de elementos procedentes de tipos gráficos anteriores, como es la reduplicación de "t", "s" o "f” que se mantendrán hasta la humanística.

Por su parte, hay que señalar que se produce una mayor proliferación de las abreviaturas y una abundante presencia de nexos, entre los cuales es frecuente la unión de "tr", con la fuga de esta última letra muy descendente, como podemos ver en la palabra "trayda" de la documentación.

En cuanto a la escritura "procesal", presente en la tercera de las unidades documentales presentadas y en algunos rasgos escriturarios de las otras dos, hemos de señalar que surge como evolución lógica de la letra cortesana, con la que convive durante algún tiempo. Fue muy común durante los siglos XVI y XVII en documentos emanados de las escribanías públicas y de los tribunales judiciales, especialmente en los procesos jurídicos, de ahí su nombre, con el que fue conocida en la propia época.

Convivió también desde mediados del siglo XVI con la escritura humanística, tipo gráfico procedente de Italia que en la Monarquía Hispánica se desarrolló especialmente en ambientes cultos y eclesiásticos y que con el tiempo terminaría por imponerse.

La letra "procesal" o "procesada" destaca por su alto grado de cursividad, la gran cantidad de trazos superfluos y bucles, así como por su irregularidad y arbitrariedad, tanto en el uso de las abreviaturas y de los signos generales de abreviación, como en la separación de las letras y palabras, dada la rapidez con la que se escribía. Ello hacía muy complicada su lectura, máxime en una sociedad casi analfabeta donde el dominio de la escritura recaía en los profesionales de la misma (escribanos o notarios, amanuenses...) y en miembros del estamento eclesiástico y nobiliario. De hecho, la propia reina Católica, en las Ordenanzas de 1503 antes citadas reguladoras de la institución notarial, art. 7, indicaba que la expedición de originales y copias autenticadas se hiciese obligatoriamente "en buena letra cortesana e no procesada". Hasta tal punto llegaba su deformación que el propio Cervantes señalaba por boca de don Quijote que este tipo de letra "no la entenderá Satanás” (parte I, cap. XXV). ${ }^{10}$

10 CERVANTES Y SAAVEDRA, Miguel: El ingenioso hidalgo don Quijote de la Mancha, Madrid, 1609, parte I, cap. XXV. Es interesante la distinción que don Quijote hace en estas líneas entre los escribanos, profesionales de la escritura (que cobraban por ello), que hacían la letra procesada que no la entendía ni el mismísimo Satanás, frente a los sacristanes o maestres de escuela, que hacían una letra más cuidada, probablemente humanística. 
De ella derivó la procesal encadenada, surgida como consecuencia del deseo de los escribanos de no levantar la pluma del papel en todo el renglón de escritura, dada la rapidez con la que se escribía. Se trata de una letra poco elegante, con gran cantidad de abreviaturas, nexos y ligaduras. A nivel gráfico destaca la forma "e", que puede hacer función de "e", "c", "s", "x", "b" o "v", así como la "c" procesal y la "o" precedida de paréntesis a principio de palabra procedente, de la cortesana.

Particularizando en las escrituras de Juan Avellán y de Diego de Lisbona, que son los escribanos que (junto con sus amanuenses, escribientes o aprendices cuya letra observamos en estos documentos) se encargan de la puesta por escrito del acto jurídico determinado, hemos de decir que Juan Avellán utiliza una escritura más encuadrada y cuidada y, por tanto, menos cursivizada, que Diego de Lisbona. Ello podría deberse esencialmente al uso de un instrumento escriptorio diferente (pluma cortada a bisel). Por su parte, la escritura de Diego de Lisbona es típicamente procesal, trazada con rapidez y cursividad, denotando gran pericia y profesionalidad en el manejo de la pluma.

Tanto uno como otro tienen como soporte material de su escritura el papel. Se trata de un papel de tipo occidental o italiano, ya que sus puntizones (improntas dejadas por el molde en sentido longitudinal) y corondeles (improntas perpendiculares a los puntizones, de mayor grosor y a mayor distancia entre sí que los puntizones), tienen un trazo recto, y, además, presenta filigrana, destacando la forma de la mano. ${ }^{11}$ Por otro lado, hay que incidir en que se trata de un papel, en general, de bastante buena calidad, ya que predomina el papel de mayor gramaje, fabricado a base de fibras textiles de lino y cáñamo de una gran consistencia, habiendo de imputarse los aspectos de deficiente conservación, no tanto al soporte escriturario, sino más bien a la acción de agentes externos, incluido el ser humano, y a la mala calidad de las tintas empleadas, en general de colores ocre y negra y caracterizadas por su componente ferrogálico que afecta al papel.

Finalmente, en lo que se refiere a las peculiaridades de la documentación presentada desde el punto de vista diplomático, teniendo en cuenta que la piedra angular de la diplomática notarial gira en torno al estudio de las tipologías documentales emanadas de las escribanías, podemos señalar en este sentido que contamos con una carta de partición de bienes (documento 1), y dos actas notariales (un acta de petición de conformidad de compraventa e información de testigos, el $\mathrm{n}^{\circ} 2$; y un acta de entrega de bienes, el $\mathrm{n}^{\circ} 3$ ). La selección se ha realizado teniendo en cuenta precisamente la variedad tipológica de la documentación, además de otros aspectos como su interés desde el punto de vista histórico, lingüístico o contextual. En general, podemos decir que los tres documentos seleccionados (y, más ampliamente, todos los que se encuentran en los volúmenes de los registros) se enmarcan perfectamente en las clasificaciones que sobre las tipologías documentales notariales han realizado los especialistas en el tema, especialmente José Bono Huerta. ${ }^{12}$

11 No vamos a entrar aquí ahora en el estudio de las mismas, que sería lo ideal para su datación y constatación de origen, entre otros aspectos. Véanse los estudios al respecto.

12 BONO HUERTA, J.: Historia del Derecho Notarial Español. I-1: Edad Media. Introducción preliminar y fuentes (Madrid, 1979), y I-2: Literatura e Instituciones (Madrid, 1982). También podrían destacarse otros de los estudios de este magno investigador, pionero en el tema. Hemos de señalar, no obstante, que, como es evidente, no todos los tipos documentales se encuentran en los registros notariales de los que venimos hablando y que, a veces, la determinación o clasificación de un tipo documental es, cuanto menos, dificultosa, debido a múltiples factores. 
Con respecto a la tradición documental, destacaré que las tres unidades documentales reproducidas son, desde el punto de vista diplomático, traslados o copias autorizadas (marcadas en las regestas con B), lo que sabemos por los signos de validación empleados y lo que es muestra de la naturaleza de los propios registros. No entraremos aquí más a fondo en cuestiones diplomáticas, que darían para un trabajo de mayores dimensiones, remitiendo para ello a las regestas que acompañan a cada unidad documental, así como a las descripciones de los signos notariales que las acompañan.

\section{NORMAS DE TRANSCRIPCIÓN}

- Se ha actualizado la puntuación, la acentuación y el uso de mayúsculas al sistema actual, con objeto de hacer más entendible el texto.

- La separación de palabras se ha actualizado cuando su unión es arbitraria.

- Los cambios de folio se indican con dos barras oblícuas (//) seguidas del número de folio, señalando si es recto (r) o vuelto (v).

- Las palabras o frases que aparecen interlineadas o sobrepuestas se colocan entre paréntesis angulares $(<>)$, mientras que las repetidas aparecen entre dos líneas oblicuas convergentes hacia abajo $(\backslash /)$, indicándose no obstante en notas al pie la circunstancia de la sobreposición o repetición.

- Las tachaduras se consignan generalmente en notas al pie de página, con objeto de no entorpecer la lectura del texto.

- Los espacios en blanco, manchados y roturas se indican entre corchetes del tenor [en blanco], [manchado], [roto], etc. tras puntos suspensivos entre corchetes [...] indicativos del texto que falta, o texto que se intuye. Por ejemplo: [...] [roto], [dicho] [manchado]. No obstante, también se recurre a las notas al pie para realizar algunos comentarios considerados necesarios para la interpretación del texto, así como para aclarar el significado de algunas palabras o pasajes dificultosos.

- Las anotaciones al margen se indican de la siguiente manera: las del margen izquierdo mediante la fórmula: [Margen izquierdo:] (Anotación); y las del margen derecho con la fórmula [Al margen:], tras el texto principal.

- Del mismo modo, la fórmula $[s i c]$ indica que se ha transcrito tal cual lo que puede parecer un error del transcriptor o mala interpretación.

- En cursiva y entre paréntesis se consignan notas aclaratorias o llamadas de atención sobre el texto.

- Las abreviaturas se han desarrollado, indicando en letra cursiva la parte abreviada añadida.

- La doble /r/ característica de las góticas, tanto al principio como a mitad de palabra, se ha transcrito por una sola cuando su uso es considerado actualmente como improcedente.

- La grafía /u/ - /v/, se ha transcrito según su valor fonético actual.

- La grafía /i/ - /j/ se ha transcrito según su valor fonético actual.

- La /n/ con signo general de abreviación se ha transcrito por $/ \tilde{n} /$.

- La /x/ de la abreviatura "Xpo" (Xrispto, Xrisptóval...), se ha sustituido por su correspondiente forma latina $/ \mathrm{Ch} /$. 
- En el resto de los casos, se ha respetado la grafía tal cual aparece en el texto (por ejemplo, en el caso de $/ \mathrm{x} / \mathrm{y} / \mathrm{j} /)$.

- Los números se han transcrito tal cual, los romanos en romanos, y los arábigos, en arábigo, si bien en el caso de los números romanos, se reproducen todos en mayúsculas, con objeto de diferenciarlos del resto del texto.

- Por lo demás, se siguen las normas de la Comisión Internacional de Diplomática ${ }^{13}$ para la edición de este tipo de documentos. Ello no quita para que cada documento se acompañe de los folios en los que se sitúa en el conjunto del volumen en que se inserta.

\section{APORTACIÓN DOCUMENTAL}

1494, septiembre, 16. Lorca.

Juana de Pina, mujer de Pedro de Tudela, difunto, y Diego de Tudela, como curador de Hernán de Tudela, Catalina Pérez y Constanza Pérez de Tudela, menores; realizan partición de los bienes muebles y raíces del dicho difunto ante Juan Avellán, escribano de cámara y del número de Lorca.

B: AHML, protocolo 1770. Carta de partición de bienes. Papel, 310 x 222 mm (290 x $180 \mathrm{~mm}$ ), fols. 292r-295r. Buena conservación, pese a que presenta algunas manchas de humedad de poca importancia que no impiden la lectura del texto. Tinta ocre. Letra gótica cursiva documental denominada "cortesana" con caracteres procesales. Lengua castellana. En el folio $295 \mathrm{r}$ presenta suscripción y signo notarial, en módulo pequeño, y en posición central, cruz griega inserta en una cuadrícula, de la que emanan doble tetrapétala entrelazada, cubriendo los vértices internos de la misma mediante formas polilobuladas con trazo decorativo en medio de las mismas. Comienza el trazado del signo después de la raíz Sig - vértice izquierdo-, que complementa con su terminación - notarial - vértice derecho-. Presenta también rúbrica del dicho notario.

Pub.(en parte): GARCÍA DÍAZ, I., Documentación medieval del Archivo Municipal de Lorca (1257-1504). Estudio y edición, Univesidad de Murcia-Ayuntamiento de LorcaReal Academia Alfonso X El Sabio, Murcia, 2007, pp. 326-330. No se trancribe el documento completo.

13 Vid. VV.AA.: Diplomatica et Sigillographica : travaux preliminaires de la Commission Internationale de Diplomatique et de la Commission Internationale de Sigillographique pour une normalisation internationale des éditions de documents et un Vocabulaire international de la Diplomatique et de la Sigillographie, Folia Caesaraugustana, 1, Zaragoza : Institución "Fernando el Católico, 1984, pp. 75-93 especialmente. Más actualizado: CÁRCEL ORTÍ, María Milagros (Ed.): Vocabulaire International de la Diplomatique, Comission Internationale de Diplomatique, Comité Internationale des Sciences Historiques, $2^{\mathrm{a}}$ Ed., Valencia, Universidad de Valencia, 1997. 
292rPartiçión Juana de Pina Diego de Tudela

$$
\begin{gathered}
(\mathrm{Cruz})+ \\
(\text { Líneas de invalidación de parte superior de folio) }
\end{gathered}
$$

En la noble çibdad de Lorca, dies e seys días del mes de setienbre, año del nuestro [sic] nasçimiento del Nuestro Salvador Ihesu Christo ${ }^{14}$ de mill e quatroçientos e noventa e quatro años, este dicho día se juntaron a faser partiçión e devisyón de los bienes y herencia que fueron e fincaron apres fin lapres fin/15 de Pero Tudela, defunto, que Dios aya, de los bienes de aquel commo de los bienes quél y Juana de Pina, su mujer, que es presente, ovieron mejorado. Para la qual dicha partiçión, se juntaron, de la una parte, la dicha Juana de Pina, por sy, e de la otra parte, Diego de Tudela, en nonbre e commo curador que es deçernido ${ }^{16}$ por el honrrado Antón Bernal, alcalde tienyente [sic] de corregidor desta dicha çibdad; de Hernán de Tudela e de Catalina Pérez e de Gostança Pérez de Tudela, menores, fijos que fincaron del dicho Pero Tudela e de la dicha Juana de Pina.

Et los bienes propios que fueron del dicho Pero Tudela son estos que se syguen, que declaró la dicha Juana de Pina:

Primeramente,

Dos tahúllas de terra en Alcalá, que afrentan con Miguel e con Juan de Tudela e con el açequia de Alcalá.

Yten una tenaja de tener vino que cogen fasta veynte arrovas, questá quebrada.

Un pedaço de secano en ${ }^{17}$ Buxercal que coje fasta dos fanegas.

Dos lanças, tiénelas Pero de Pina.

Una espada con su guarniçion, tiénela Pero de Pina, su ahuelo, que asy lo confesó el dicho Pero de Pina.

[Al margen izquierdo, misma mano:] (Deve la madre). Una capa de Brujas que dixo Juana de Pina, que la vendió ella por seteçientos maravedís. [Al margen:] DCC

Unas coraças, dixo Pero de Pina que heran de Gonzalo Manchirón, que le fueron dadas. Un capaçete ${ }^{18}$ e una bavera. ${ }^{19}$

Un adarga ${ }^{20}$ de anta. $^{21}$

14 Latinización de la forma griega "Xpo".

15 Repetido.

16 Decernir: forma antigua de discernir, aquí con el significado de "conceder u otorgar cargo, distinción u honor". (Diccionario de la Lengua Española, 22 Ed., Madrid, 2001).

17 Mancha de humedad que dificulta la lectura de "en".

18 Capacete. (Del fr. cabasset). 1. m. Pieza de la armadura, que cubría y defendía la cabeza. (Diccionario de la Lengua Española, $22^{\mathrm{a}}$ Ed., Madrid, 2001).

19 Babera. (De baba ). 1. f. Pieza de la armadura antigua que cubría la boca, barba y quijadas. (Diccionario de la Lengua Española, 22 ${ }^{\mathrm{a}}$ Ed., Madrid, 2001).

20 Adarga (Del ár. hisp. addárqa, y este del ár. clás. daraqah). 1. f. Escudo de cuero, ovalado o de forma de corazón. (Diccionario de la Lengua Española, 22 ${ }^{\text {a }}$ Ed., Madrid, 2001).

21 Un tipo de cuero. 


\section{(Línea de invalidación de folio) //292v}

\section{(Lineas de invalidación de la parte superior del folio)}

[Al margen izquierdo, misma mano:] (Deve esto la madre). Yten treze hanegas de trigo que se falló que la dicha Juana de Pina resçibió por los dichos sus fijos de los bienes de [cambio de mano] Sancho Péres [sigue la mano anterior] de Tudela, su aguelo, e quatro fanegas de çevada, lo qual se halló que la dicha Juana vendió a çiento la hanega del trigo e çinquent $a$ la fanega de la çevada sygund que ella ${ }^{22}$ lo confesó. [Al margen:] IU D [Al margen izquierdo, misma mano:] (Mejoramiento). Los bienes que los dichos Pero Tudela e su mujer Juana de Pina ovieron mejorado durante su matrimonio son los syguientes:

[Al margen izquierdo, misma mano:] (A los herederos). Primeramente, una casa con su cámara ençima en la collaçión de señora Santa María, que afrenta con casas de la dicha Juana de Pina, e de la otra parte con casas de Pero Sánches de Pina e con la calle pública, apreçiada en mill e quinientos maravedís. [Al margen:] IU D

[Al margen izquierdo, misma mano:] (A los herederos). Yten el hedefiçio que los dichos Pero Tudela e su mujer ovieron mejorado e hedificado en unas casas de la dicha Juana de Pina, en la dicha colaçión de señora Santa María, apreçiado en dos mill e quinientos maravedís. [Al margen:] IIU D

[Al margen izquierdo, misma mano:] (A la madre). Yten tres tahúllas en Alcalá con dos tahúllas de agua de los miércoles, que afrentan con Juan Helizes, las quales se fallaron que la dicha Juana de Pina ovo vendido siendo biuda, después que fallesçió el dicho su marido e en dis días, por tres mill e tresientos maravedís. [Al margen:] IIIU CCC

[Al margen izquierdo, misma mano:] (A la madre). Yten un cavallo de pelo ruán ensillado e enfrenado, que se halló que la dicha Juana de Pina ovo vendido después que el dicho su marydo fallesçió por seys mill maravedís. [Al margen:] VIU

[Al margen izquierdo, misma mano:] (A los herederos). Yten dos mantas nuevas, la una blanca e la otra listada, apreçiadas la blanca porque dixo la dicha Juana de Pina que después de biuda las ovo dado a Pero de Pina, su padre, para pagar çierta debda quel dicho su padre devya, en mill maravedís. [Al margen:] IU

\section{(Validación notarial) //293r}

[Al margen izquierdo, misma mano:] (A la madre). Un poyal ${ }^{23}$ que la dicha Juana de Pina dixo que vendió syendo byuda por çiento e çinquenta maravedís. [Al margen:] C L

[Al margen izquierdo, misma mano:] (A la madre). Tres sávanas de lino de dos telas e media cada una de peyne ancho que avie en ellas veynte e dos varas e media, a treynta maravedís la vara, que montan seysçientos e setenta e çinco maravedís. [Al margen:] DC LXXV maravedis

22 Tinta desvaída.

23 Poyal. 1. m. Paño listado con que se cubren los poyos en algunos lugares. (Diccionario de la Lengua Española, 22a Ed., Madrid, 2001). 
[Al margen izquierdo, misma mano:] (A la madre). Un par de manteles de lino de tableros, de quatro varas, çiento e sesenta maravedís. [Al margen:] C LX maravedís

[Al margen izquierdo, misma mano:] (A los herederos). Una caldera de aranbre que coge un cántaro de agua, en dosientos maravedís. [Al margen:] CC maravedís

[Al margen izquierdo, misma mano:] (Dévelo Pero de Pina). Un aradro de azémilas con su reja en çiento y treynta maravedís. [Al margen:] C XXX maravedís

[Al margen izquierdo, misma mano:] (A la madre). Dos cadiras ${ }^{24}$ de costillas en çinquenta maravedís. [Invalidación de renglón] [Al margen:] L maravedís

[Al margen izquierdo, misma mano:] (A la madre). Una mesa con sus pies en quarenta maravedís. [Al margen:] XL maravedís

[Al margen izquierdo, misma mano:] (A la madre). Un arca de madera de pyno pequena con su çerradura en çient maravedís. [Al margen:] C maravedís

[Al margen izquierdo, misma mano:] (A los herederos). Yten un corralejo questá junto con la dicha casa cámara en la dicha colaçión de Santa María, que se falló que la dicha Juana de Pina conpró del dicho su padre con la meytad de una casa questá junto con el dicho corral en las casas del dicho Pero de Pina, en mill maravedís. [Al margen:] IU maravedis

[Al margen izquierdo, misma mano:] (A los herederos). Yten una vánova ${ }^{25}$ nueva en mill e quinientos maravedís. [Al margen:] IU D maravedís

[Al margen izquierdo, misma mano:] (A los herederos). Yten un paramento ${ }^{26}$ de figuras que ay veynte e quatro varas, nuevo, a veynte maravedís la vara, que montan quatrosientos e ochenta maravedís. [Al margen:] CCCC ${ }^{\circ} \mathrm{LXXX}$ maravedís

[Al margen izquierdo, misma mano:] (A la madre). Un poyal, otro, en çiento e çinquenta maravedís. [Al margen:] C L maravedís

[Al margen izquierdo, misma mano:] (A los herederos). Una artesa grande en çinquenta maravedís. [Al margen:] L maravedís

[Al margen izquierdo, misma mano:] (A la madre). Una artesa pequena en çinquenta maravedís. [Al margen:] L maravedís

[Al margen izquierdo, misma mano:] (A los herederos). Yten un corral exido ${ }^{27}$ a espaldas de las dichas casas, que afrentan con la barvacana del castillo en çient maravedís. $\lfloor A l$ margen:] C maravedís.

(Línea de invalidación de folio) //293v

24 Cadira (del lat. cathedra). 1. f. desus. silla con respaldo. (Diccionario de la Lengua Española, 22 ${ }^{\mathrm{a}}$ Ed., Madrid, 2001).

25 Vánova (Del b. lat. vanoa; cf. prov. vano). 1. f. rur. Hues. Colcha o cubierta de cama. (Diccionario de la Lengua Española, 22 ${ }^{\mathrm{a}}$ Ed., Madrid, 2001).

26 El Diccionario de la Real Academia recoge para paramento. (Del lat. paramentum). 1. m. Adorno o atavío con que se cubre algo. 2. m. Sobrecubiertas o mantillas del caballo. 3. m. Arq. Cada una de las dos caras de una pared. 4. m. Constr. Cada una de las seis caras de un sillar labrado. Por el contexto me inclino por la primera o segunda acepción. (Diccionario de la Lengua Española, 22 ${ }^{\mathrm{a}}$ Ed., Madrid, 2001).

27 Ejido (Del lat. *exìtus, por exītus, salida). 1. m. Campo común de un pueblo, lindante con él, que no se labra, y donde suelen reunirse los ganados o establecerse las eras. (Diccionario de la Lengua Española, 22 ${ }^{\mathrm{a}}$ Ed., Madrid, 2001). 


\section{(Líneas de invalidación de la parte superior del folio)}

[Al margen izquierdo, misma mano:] (A los herederos). Dos tenajas de tener vino que coje fasta treze arrovas cada una, en dozientos maravedís. (Al margen): CC maravedís [Al margen izquierdo, misma mano:] (A los herederos). Yten quatorze reales castellanos que ovo resçibido Pero de Pina prestados que le prestó la dicha Juana de Pina de bienes de común della y de su marido. Los quales el dicho Pero de Pina conosçió que los reçibió y los debe, que montan quatrosientos e treynta e quatro maravedís. [Al margen:] $\mathrm{CCCC}^{\circ} \mathrm{XXXIIII}$ maravedís

[Al margen izquierdo, misma mano:] (Número de mejoros). Asy que suman e montan los dichos bienes rayzes e muebles que los dichos Pero Tudela e Juana de Pina ovieron durante su matrimonio, en suma maior, dies $\mathrm{e}^{28}$ nueve mill e seteçientos e sesenta e nueve maravedís. [Al margen:] XIXUDCCLXIX

[Al margen izquierdo, misma mano:] (Por parte). Los quales dichos dies e nueve mill e seteçientos e sesenta maravedís que asy montan los dichos bienes de mejoramientos, fechos en dos partes, la meytad para la dicha Juana de Pina e la otra meytad para los dichos sus fijos, viene a cada meytad a nueve mill e ochoçientos e ochenta e quatro maravedís e medio. [Al margen:] IXUDCCC ${ }^{\circ} \mathrm{LXXX}^{\mathrm{O}}\left[\mathrm{IIII}^{\circ}\right]^{29}$ medio

[Al margen izquierdo, misma mano:] (Pagos a los herederos). E para pagar e faser pago a los dichos herederos, fijos del dicho Pero Tudela, asy de los dichos nueve mill e ochoçientos e ochenta e quatro maravedís e medio de la meytad de los dichos mejoramientos como de los dichos dos mill e dosientos maravedís que los deve la dicha su madre, los mill e tresientos maravedís de las treze fanegas de trigo e los dosientos maravedís de las quatro fanegas de çevada que se falló que la dicha Juana de Pina, su madre, ovo de sus ahuelos de los dichos menores, e los seteçientos maravedís de la capa de Brujas del dicho Pero Tudela que se falló que la dicha Juana de Pina ovo vendido; que son e montan todos lo que los dichos herederos an de aver y ser entregados doze mill e ochenta e quatro maravedís e medio, les dieron e pagaron en estos bienes que se syguen: [Al margen:] XIIULXXX ${ }^{\circ}\left[\mathrm{IIII}^{\circ}\right]^{30}$

\section{(Validación notarial) //294r}

(Líneas de invalidación de la parte superior del folio)

Primeramente,

Les dieron las dichas casas contenidas en esta partiçión, con los hedefiçios de las que están en quatro mill maravedís. [Al margen:] IIII ${ }^{\circ} \mathrm{U}$ maravedís

Yten les dieron el otro corralejo con la meytad de la casa que está junto con las casas de suso, que se ovo conprado del dicho Pero de Pina, su ahuelo en mill maravedís. $\mid A l$ margen:] IU maravedís

28 Tachado a continuación "s".

29 La encuadernación posterior tapa los numerales, que los intuimos por su desarrollo escrito inmediatamente anterior.

30 Ídem. 
Yten les dieron el dicho corral exido que está a espaldas de las dichas casas fasta el castillo en çient maravedís. [Al margen:] C maravedís

Yten les dieron en el dicho Pero de Pina, su ahuelo, los mill maravedís de las dos mantas que aquel debe. [Al margen:] IU maravedis

Yten la caldera en dosientos maravedís. [Al margen:] CC maravedís

Yten el aradro [sic] con su reja que deve el dicho Pero de Pina en çiento e treynta maravedís. [Al margen:] C XXX maravedís

Yten les dieron la dicha vánova en mill e quinientos maravedís. [Al margen:] IUD maravedís

Yten les dieron el paramento de figuras en quatroçientos e ochenta maravedís. \Al margen:] $\mathrm{CCCC}^{\circ} \mathrm{LXXX}^{\circ}$ maravedís

Yten el artesa grande en çinquenta maravedís. [Al margen:] L maravedís

Yten las dos tenajas de tener vino de fasta treze arrovas cada una en dosientos maravedís. [Al margen:] CC maravedís

Yten les dieron que cobren del dicho Pero de Pina, su ahuelo, los catorze reales que ovo resçibido prestados de la madre de los dichos menores. [Al margen:] $\mathrm{CCCC}^{\circ} \mathrm{XXXIIII}{ }^{\circ}$ maravedis

Más les dio la dicha su madre una sartén de aranbre en çient maravedís y una arca de pino en dosientos maravedís, que son tresientos maravedís. [Al margen:] CCC maravedís

(Línea de invalidación de folio) //294v

[Al margen izquierdo, misma mano:] (Debda que les deve la madre). Asy que les faltan a los dichos herederos para ser entregados de lo que asy an de aver como de suso es dicho, les faltan dos mill e seysçientos e noventa maravedís e medio, los quales an de aver de la dicha Juana de Pina su madre. [Al margen:] IIUDCXC maravedís medio

[Al margen izquierdo, misma mano:] (Pago de la dicha madre). E para faser pago a la dicha Juana de Pina de los dichos nueve mill e ochenta e quatro maravedís e medio que ha de aver de los dichos mejoramientos, le fueron dados y entregados en estos bienes que se syguien: [sic] [Al margen:] IXU LXXX'IIII' maravedís medio

\section{Primeramente,}

Le dieron las dichas tres tahúllas de tierra de Alcalá que ella ovo vendido en tres mill e tresientos maravedís. [Al margen:] III U CCC

Yten le adjuzgaron los seys mill maravedís del cavallo que ella ovo resçibido. [Al margen: ] VI U

Yten un poyal en çiento e çinquenta maravedís. [Al margen:] CL

Yten las tres sávanas de lino en seysçientos e setenta e çinco maravedís. [Al margen:] DCLXXV

Yten el par de manteles de lino en çiento e sesenta maravedís. [Al margen:] C LX

Yten las cadiras en çinquenta maravedís. [Al margen:] L

La mesa con sus pies en quarenta maravedís. [Al margen:] XL

Yten el arca en çient maravedís. [Al margen:] C 
El otro poyal en çiento e çinquenta maravedís. [Al margen:] CL

El artesa pequeña en çinquenta maravedís. [Al margen:] L

Asy que desta manera susodicha es contenta e pagada la dicha Juana de Pina, y queda deviendo a los dichos sus fijos los dichos dos mill e seysçientos e noventa maravedís e medio que aquellos tienen de menos y les faltan por cobrar de lo que ellos avían de aver, como dicho es de suso. Los quales [Invalidación de folio mediante línea y rúbrica notarial] //295r (NOTA 31) dos mill e seysçientos e noventa maravedís e medio, yo, la dicha Juana de Pina, se obligó por sy e sus bienes de los dar e pagar a los dichos sus fijos e al dicho Diego de Tudela, su tutor e curador de aquellos, que es presente, e para aquellos ecaetera, del día de oy e de la fecha desta dicha partiçión fasta un año primero syguiente, ecaetera. Para lo qual dio poder a las justiçias, renunçió las leyes ecaetera, e otorgó carta de obligaçión, ecaetera, e asy mismo las dichas dos partes otorgaron carta de partiçión como de suso es fecha, ecaetera. Testigos que fueron presentes, Pero de Pina e Francisco Ruvio e Pero de Çiguentes, vesinos de la dicha çibdad de Lorca [A continuación, cambio de mano]. E yo, Juan Avellán, escrivano de cámara de Sus Altezas e su notario público en la su corte y en todos los sus regnos e señoríos e escrivano del número desta dicha çibdad, que al faser e otorgar desta dicha carta de partiçión e a todo lo en ella contenydo, en uno con las sobredichas partes e testigos presente fuy. E por virtud del dicho otorgamiento e de pedimiento de Bartolomé Corvillo, marido de la dicha Gostança Péres de Tudela, esta dicha escriptura e partiçión fise sacar e escrevyr en esta pública forma segund que ante mí pasó. E por ende, en testimonio de verdad, fiz aquí este myo acostunbrado sig(signo)notarial.

\author{
Juan Avellán, \\ escrivano (Rúbrica) //
}

2

1508, febrero, 23. Lorca.

Diego de Chuecos, vecino de Lorca, comparece ante Pedro Guil, alcalde lugarteniente de justicia de Lorca, testimoniando la compra de media hora de agua a Juan Gabarrón mediante la presentación de una carta de venta que pide sea dada por buena, y respuesta del alcalde solicitando la presencia de testigos, los cuales presenta en rebeldía.

B: AHML, protocolo 1770. Acta de petición de conformidad de compraventa e información de testigos. Papel, 310 x 222 mm (290 x 180 mm), fol. 288r/v. Regular conservación,

31 Aquí concluye la transcripción de Isabel GARCÍA DÍAZ, Documentación medieval del Archivo Municipal de Lorca (1257-1504). Estudio y edición, Univesidad de Murcia-Ayuntamiento de Lorca-Real Academia Alfonso X El Sabio, Murcia, 2007, pp. 326-330. La autora da al documento por incompleto en la regesta (p. 326), cuando he podido comprobar que no es así, por lo que se añade su final transcrito con el signo y rúbrica autógrafa del notario Juan Avellán. 
ya que presenta roturas de la materia escriptoria por comeduras de polilla en la parte superior del folio y manchas de humedad. Tintas ocre y negra. Letra gótica cursiva documental denominada "cortesana". Lengua castellana.

${ }^{288 r}$ En la noble çibdad de Lorca a XXIII de febrero de IUDVIII años.

Este día, antel senor bachiller Pero Guil, alcalde lugarteniente de justiçia en esta noble çibdad de Lorca por el ynlustre e manífico senor don Pedro Fajardo, marqués de Veliz, Adelantado e Capitán en el reyno de Murçia e justiçia mayor en él por la reyna dona Juana, nuestra señora, e en presençia de mí, Diego de Lisbona, escrivano, e testigos yuso escriptos, paresçió presente Diego de Chuecos, veçino desta çibdad, e dixo quél ovo conprado e conpró media ora de agua de Juan Gavarrón, veçino desta çibdad, por cierto preçio, de la qual carta de venta fizo presentaçión; que pedía e requería al señor alcalde le mande fazer sana e buena por quanto a él le pide la dicha ${ }^{32}$ media ora de agua, por quanto aquél no es abonado en esta çibdad e se quiere yr e absentar della e asy lo pidió por testimonio.

El señor alcalde dixo que le diese testigos de ynformaçión cómo no es abonado e se quiere yr el dicho Juan Gavarrón. E quél es presto de fazer lo que fuere justiçia.

En después de lo suso dicho, en la dicha çibdad de Lorca, antel dicho senor alcalde, e en presençia de mí, el dicho escrivano, e testigos yuso escriptos, paresçió presente Diego de Chuecos, veçino desta çibdad, e dixo que por quanto él tiene enplazados para esta abdiençia a Gonçalo de Setiel e Garçía de Juan Gil e a la muger de Juan Gavarrón e Antonio Sastre, e aquellos no an paresçido, que le acusa la reveldía, de la qual dio fee Juan de Çamora que los enplazó para esta abdiençia. En su reveldía los presentó por testigos.

El señor teniente los reçibió e mandó que para el juramento los trayga antél.

Testigos Diego Avellán e Rodrigo de Antolinos. //288v

[Al margen izquierdo:] Testigo: María de Herrera, muger del dicho Juan Gavarrón, testigo presentado por el dicho Diego de Chuecos, aviendo fecho juramento en forma devida de derecho e seyendo preguntado segúnd el tenor e forma del dicho pedi[mi]ento, ${ }^{33}$ dixo que sabe quel dicho Juan Gavarrón no es abonado ni raygado ni tiene bienes ningunos muebles nin rayzes en esta çibdad, e que sabe que aquel sí es ydo della a los Alunbres e que no sabe sy se verná o no, e questa es la verdad para la jura que fecho tiene.

El dicho Garçía de Juan Gil, testigo de ynformaçión presentado por el dicho Diego de Chuecos, ${ }^{34}$ seyendo preguntado segúnd el tenor e forma del dicho pedimiento, dixo que sabe quel dicho Juan Gavarrón no tiene bienes en esta çibdad muebles nin rayzes ningunos, e queste fue a los Alunbres, e que no sabe si se vendrá o no, e questa es la verdad. El dicho Gonçalo de Setiel, testigo de ynformaçión presentado por el dicho Diego de Chuecos, seyendo preguntado segúnd el tenor e forma del dicho pedimiento, dixo que

32 Tachado a continuación "o md".

33 Rotura por comedura de polilla.

34 Tachado a continuación "aviendo". 
sabe quel dicho Juan Gavarrón no tiene bienes muebles ${ }^{35}$ nin rayzes en esta çibdad, ni en qué caer muerto; e ques onbrre que oy está aquí e mañana allí, e que le vendía a este testigo una espada para yrse a Moxácar e questo sabe para el juramento que fecho tiene. El sennor alcalde mandó dar su mandamiento para raygar de fianças al dicho Juan Gavarrón para el alcalde de los Alunbres.

[Testigos Martín] [tachado]

En después de lo suso dicho, en la dicha çibdad de Lorca [...] [se corta] //

3

1511, abril, 15. Lorca.

Martín de León, curador de Francisco de Cerezuela, entrega al curador de éste, Bernad de Cerezuela, los bienes que había tenido en su poder, procedentes de la partición de aquél; ante Diego de Lisbona, escribano y notario público de Lorca.

B: AHML, protocolo 3. Acta de entrega de bienes. Papel, 310 x 222 mm (290 x $180 \mathrm{~mm})$, fols. 241r-242v. Buena conservación, salvo excretas de insectos y mancha de humedad al final del folio $2 \mathrm{v}$ que dificulta la transcripción del texto. Tinta ocre clara. Letra gótica cursiva documental denominada "procesal". Lengua castellana.

$$
241 \mathrm{r}(\text { Cruz })+
$$

(Sobre la invocación, en letra bastarda del XVIII): (Dote de Françisco Carteruela [sic])

En la noble çibdad de Lorca, quinze días del mes de abril, de mill e quinientos e onze años; este dicho día, en presençia de mí, Diego de Lisbona, escrivano e notario público en esta dicha çibdad e uno de los escrivanos del número della e de los testigos yuso escriptos; Martín de León, curador de Françisco de Çerezuela, dio e entregó los bienes que tenía del dicho Françisco de Çerezuela e avya reçibido en ${ }^{36}$ la partiçión del susodicho. Los quales dichos bienes se los dio e entregó a Bernad de Çerezuela, curador del dicho Françisco de Çerezuela. La qual dicha cura pasante en la forma e manera syguiente:

Yten unas cabeçadas esmaltadas con sus cordones.

Yten una rastra de corales pequenos.

Yten un çenidor.

Yten un almayzal ${ }^{37}$ enrexado ${ }^{38}$ pequeno de lana colorada.

35 Tachado a continuación "e".

36 Tachado a continuación "cuenta".

37 Almaizal: toca de gasa usada por los moros. (Diccionario de la Lengua Española, 22a Ed., Madrid, 2001).

38 Enrejado: 4. m. Labor de manos que se hace formando varios dibujos, como hilos o sedas entretejidos y atravesados. (Diccionario de la Lengua Española, 22ª Ed., Madrid, 2001). 
Yten dos orillas de alquinal coloradas.

Yten un guante de malla.

Yten tres cabeças ${ }^{39}$ las dos grandes e la una pequeña.

Yten seys sargas colorada ${ }^{40}$ e amarillas e verdes.

Yten una vánova blanca de lana vieja.

Otra vánova mueva. [sic] //241v

Yten una alfonbra de veynte palmas de lana vieja.

Yten un poyal muevo [sic] con listas amarillas e verdes.

Yten seys almohadas de alfonbra [con] [manchado] sus suelas e syn suelo.

Yten otras tres almohadas en pieça nuevas.

Yten una manta syn listas, çerca nueva batanada.

Yten dos tovajas destopa traydas.

Yten una cara de colchón de doze varas trayda.

Yten una almohada de lino labrada con su lana.

Yten una almarga de tres telas destopa de dies e ocho varas.

Yten una mesa de gonçes con sus pies.

Yten dos pares de chapines, los unos colorados e los otros ${ }^{41}$ negros.

Yten una sávena ${ }^{42}$ nueva de lino de dies varas e media.

Yten una pieça de panizicos de onze panizicos.

Yten un paramento de b[a]rrotes de unas pannas. [?]

Yten una sylla gineta de cavallo. //242r

$<$ Dos $>^{43}$ bancos nuevos e $<$ çinco $>^{44}$ tablas.

Lana para henchir un almadraque.

Yten unos pocos añinos ${ }^{45}$ faldas.

Yten dos calderas grandes.

Yten una ${ }^{46}$ artesa grande.

Yten dos tablas de horno e un tablero.

Yten un brasero.

Yten dos candiles.

Yten dos sartenes, ${ }^{47}$ la una de aranbre e la otra de fierro.

Yten una vara de medir de fierro.

Quatro asadores e unas grellas.

39 Probablemente por "cabeçadas".

40 Tachado a continuación "d".

41 Tachado a continuación "dorados".

42 La palabra se mantiene aún hoy día en el habla viva rural del campo de Lorca, atestiguada por mí mismo en mi propia familia. También se hizo eco de la permanencia de dicha voz ARCAS CAMPOY, María, "Inventario de bienes de una morisca granadina emigrada a Lorca (Murcia)", Al-Masaq, 4, 1991, pp. 35-49; pp. 40-41 en especial.

43 Sobrepuesta sobre "quatro" [tachado].

44 Sobrepuesta sobre "nueve" [tachado].

45 Añino: 3. m. pl. Pieles no tonsuradas de corderos de un año o menos. 4. m. pl. Lana de corderos. (Diccionario de la Lengua Española, 22 ${ }^{\mathrm{a}}$ ed., Madrid, 2001).

46 Tachado "alie-".

47 Tachado "do". 
Yten dos raseras e dos ${ }^{48}$ e un ra[e]dor ${ }^{49}$ de carabaça.

Yten unas espuelas estanadas.

Yten dos arados de bueyes.

Yten un tendido de lana viejo.

Yten unas alforjas de lana.

Yten un rastillo e una rastillica.

Yten una lança con su fierro.

Yten un açadón e un llegón [sic].

Yten un alanbin. ${ }^{50} / / 242 \mathrm{v}$

Yten un destral. ${ }^{51}$

Yten una ola de aranbre.

Yten un baçín labrado.

Yten una arca.

Yten un cofre de marca mayor pintado,

Yten otro cofre pequeño.

Yten un jarro destaño.

Yten un cavallete.

Yten un torno de filar trama.

Yten un capaçete.

Quatro horcas grandes de trillar.

Yten un çer[ni] $1^{52}$ de madera.

Yten un trillo.

Yten un brial de grana con una çerca de terciopelo.

Yten un manto de contray ${ }^{53}$ guarneçido. ${ }^{54}$

Yten un jubón de saya con las mangas de chamelo.

Yten un capus de contray.

Yten una gorra.

48 Tachado "guisques", según el Diccionario de la Lengua Española: guizque: 1. m. Palo con un gancho en una extremidad para alcanzar algo que está en alto. 2. m. Palo con regatón en un extremo y en el otro una horquilla de hierro que sirve para descansar las andas en las procesiones.

49 Rotura del papel.

50 MARTÍNEZ RUÍZ, J., Inventario de bienes moriscos en el reino de Granada (siglo XVI). Lingüística y civilización, Madrid, CSIC, 1972, pp. 46-47 recoge varios términos, entre los que podían servirnos alamía: "una alamía de algodón listado, 1566, Ferreira y Poqueira, L-101-42, f. 6r; "una bestidura morisca, de seda y de colores, que se dize ahamía", 24 dic. 1562, Ugíjar-Cástaras, L-64-4, f. 6v; "una hamía de seda, un ducado", 16 de abril 1549, Níjar-Huebro, L-64-3, f. 7r." Y señala: "No figura la palabra en COROMINAS, I, ni en G. DE DIEGO, DEEH. Sin embargo, en Marruecos (Tetuán), J. ALBARRACÍN recogió, entre otros materiales para su tesis, el nombre "jamya" aplicado a un tejido rayado de amarillo y azul sobre fondo blanco. BELOT, 183, rá. Jam "Étoffe de coton, etc. écrue".

51 Destral. (Del lat. dextrālis, de dextra, diestra, porque suele manejarse con esta mano). 1. m. Hacha pequeña que se maneja por lo general con una sola mano. (Diccionario de la Lengua Española, 22 ${ }^{\mathrm{a}}$ ed., 2001).

52 Rotura del papel.

53 Contray. (De Kortrijk, nombre flamenco de Courtrai). 1. m. Especie de paño fino. (Diccionario de la Lengua Española, 22a ed., 2001).

54 Después de la sílaba "guar-" aparece tachado "ni". 
Los quales dichos bienes reçibió Bernad de Çerezuela para dar cuenta dellos al dicho Françisco de Çerezuela. Testigos que fueron presentes Alonso Garçía de Alcaras e Fernando de Pareja, veçinos de Lorca e Juan Ferrandes de Ribavellosa a[...] [tinta desvaída, se intuye una rúbrica también]

Pasó ante mí, Diego de Lisbona, escrivano [público] ${ }^{55}$ (Rúbrica) //

\section{CONCLUSIONES}

Pese a que se antoja difícil la labor de plasmar en unas pocas páginas la importancia de los ricos registros notariales conservados en el Archivo Histórico Municipal de Lorca, esperamos haber podido a través de las mismas aportar una muestra lo suficientemente representativa del tesoro documental del que hemos hablado, llamando al mismo tiempo la atención sobre las posibilidades que dicho fondo documental abre a los investigadores por la riqueza y variedad de temas y puntos de vista que ofrece.

55 Tinta desvaída. 